\title{
A RECONSTRUÇÃO DE MEMÓRIAS DA ALIMENTAÇÃO NA FORMAÇÃO INICIAL DE PROFESSORES DE CIÊNCIAS: UM REENCONTRO COM SABERES, SABORES, AROMAS E AFETOS
}

THE FOOD MEMORIES RECONSTRUCTIONIN INITIAL SCIENCE TEACHER EDUCATION: A REUNION WITH KNOWLEDGE, TASTES, FLAVORS AND AFFECTION

LA RECONSTRUCCIÓN DE MEMORIAS DE LA ALIMENTACIÓN EN LA FORMACIÓN DE PROFESORES DE CIENCIAS: UM REENCUENTRO CON SABERES, SABORES, AROMAS Y AFECTOS

\author{
Adriana Marcela Bogado \\ Denise de Freitas
}

\begin{abstract}
RESUMO
Neste texto, discutimos diversos aspectos vinculados à alimentação a partir da análise de narrativas produzidas por estudantes do curso de Licenciatura em Ciências Biológicas, no marco de uma intervenção didática que envolveu o trabalho com a memória. Essa intervenção tinha como principal objetivo propiciar uma aproximação aos atributos socioculturais da alimentação, tanto em seus aspectos subjetivos coletivos como individuais. As narrativas foram submetidas à análise temática do conteúdo articulada a referencial sobre memória e práticas alimentares. Assim, foi possível identificar alguns aspectos relevantes que caracterizam as práticas alimentares rememoradas: a infância como momento marcante na aquisição de hábitos alimentares, ressignificada à luz do momento atual; a comensalidade reconhecida como valor; diferentes formas de expressar a subjetividade em relação aos alimentos; o protagonismo das avós na memória gustativa e afetiva, e, finalmente, a introdução de mudanças nos hábitos alimentares.
\end{abstract}

PALAVRAS-CHAVE: Alimentação. Memórias. Narrativas. Formação de professores.

\begin{abstract}
In this paper we discuss various aspects related to food from the analysis of narratives produced by students of the course of Biological Sciences Degree, as part of an educational intervention that involved working with memory. This intervention had as main objective to provide an approach to socio-cultural attributes of power, both in their collective subjective aspects as individual. The narratives were submitted to thematic analysis of articulated speech reference on memory and feeding practices. Thus, it was possible to identify some relevant aspects that characterize the eating habits recollected: childhood as a defining moment in the acquisition of eating habits, resignified the light of the present moment; the edibility recognized as a value; different ways of expressing the subjectivity in relation to food; the role of grandparents in taste and affective memory, and finally the introduction of changes in eating habits.
\end{abstract}

KEYWORDS: Feeding. Memoirs. Narratives. Teacher training. 


\section{RESUMEN}

En este texto discutimos diversos aspectos relacionados con la alimentación a partir del análisis de narrativas producidas por estudiantes del curso Licenciatura en Ciencias Biológicas, en el marco de una intervención didáctica que implicó el trabajo con la memoria. Esa intervención tenía como objetivo principal proporcionar una aproximación a los atributos socioculturales de la alimentación, tanto en sus aspectos subjetivos colectivos como individuales. Las narrativas fueron sometidas al análisis temático de contenido articulado a referencial acerca de memoria y prácticas alimenticias. De esa manera, fue posible identificar algunos aspectos relevantes que caracterizan las prácticas alimenticias recordadas: la infancia como un momento excepcional en la adquisición de hábitos alimenticios, resignificada a la luz del momento presente; la comensalía reconocida como valor; diferentes formas de expresar la subjetividad en relación a los alimentos; el protagonismo de las abuelas en la memoria gustativa y afectiva, y, finalmente, al introducción de cambios en los hábitos alimenticios.

PALABRAS CLAVE: Alimentación. Memorias. Narrativas. Formación de profesores.

“(...) dirijo-me para as planícies e os vastos palácios da memória, onde estão tesouros de inumeráveis imagens veiculadas por toda a espécie de coisas que se sentiram. Aí está escondido também tudo aquilo que pensamos, quer aumentando, quer diminuindo, quer variando de qualquer modo que seja as coisas que os sentidos atingiram, e ainda tudo aquilo que lhe tenha sido confiado, e nela depositado, e que o esquecimento ainda não absorveu nem sepultou. Quando aí estou, peço que me seja apresentado aquilo que quero [...] " Confissões de Santo Agostinho

\section{INTRODUÇÃO}

Neste trabalho, discutimos aspectos vinculados à alimentação a partir da análise de narrativas produzidas por estudantes do curso de Licenciatura em Biologia, no marco de uma intervenção didática, que envolveu o trabalho com a memória como forma de reconstruir as lembranças de suas práticas alimentares. Sendo, na atualidade, a Educação Alimentar um conteúdo obrigatório na formação para a cidadania ${ }^{1}$, os processos educativos relacionados à alimentação precisam ter como ponto de partida o conhecimento das práticas alimentares e a compreensão dos significados atribuídos ao ato de comer. Como sinaliza Maciel (2001, p.145):

O alimentar-se é um ato vital, sem o qual não há vida possível, mas, ao se alimentar, o homem cria práticas e atribui significados àquilo que está incorporando a si mesmo, o que vai além da utilização dos alimentos pelo organismo.

No caso aqui apresentado, os/as estudantes, pela sua formação, possuíam uma familiaridade com os componentes biológicos e ecológicos da alimentação. Dessa forma, era fundamental uma aproximação aos atributos socioculturais, tanto em seus aspectos subjetivos coletivos como individuais. Para isso, optamos por explorar suas práticas alimentares, a partir da reconstrução de suas memórias. Esse processo possibilitou a emergência de lembranças

${ }^{1}$ BRASIL. Ministério da Educação. Diretrizes Curriculares Nacionais para o Ensino Médio. Resolução $n^{\circ} 2$, de 30 de janeiro 2012. Orientação para incluir a Educação Alimentar e Nutricional como tratamento transversal. 
relacionadas a aspectos marcantes da alimentação. Cabe esclarecer que essa intervenção foi parte de uma experiência mais ampla, que envolveu explorar diversas dimensões sociais, culturais, históricas, afetivas, econômicas, estéticas, etc; relacionadas à temática da alimentação, no marco de um processo de formação inicial de professores de Ciências e Biologia. Assim, este texto se constitui em um recorte, no qual focalizamos a análise nas narrativas sobre práticas alimentares reconstruídas numa intervenção didática que envolveu o trabalho com a memória.

Inicialmente, fazemos uma breve explanação apresentando o referencial que nos orientou na intervenção didática e balizou a análise aqui apresentada. Em seguida, descrevemos a intervenção realizada e o contexto no qual ela se desenvolveu. Na sequência, apresentamos a forma de análise e a organização dos dados, articulando nosso referencial sobre memória e práticas alimentares, com a análise de conteúdo temática proposta por Bardin (1977). A apresentação dos resultados está organizada em cinco tópicos: Os tempos da memória; Compartilhar a mesa; O valor dos alimentos; Comida de avó; Mudanças na alimentação. Nesses tópicos, analisamos e discutimos diversos aspectos vinculados à alimentação, evidenciados no processo de reconstrução das práticas alimentares de nossos/as narradores/as, a partir do trabalho com a memória. Finalmente, encerramos o texto tecendo algumas considerações sobre o uso da estratégia da memória na reconstrução de práticas alimentares dos licenciandos e licenciandas para a abordagem do tema na formação de professores.

\section{SOBRE ALIMENTAÇÃO, MEMÓRIA E NARRATIVAS}

Como afirma Maria Cristina Faber Boog, "a alimentação é um tema central da vida e da vida em sociedade" (2004, p.21). Desde a mais terna infância, passamos pela influência marcante da família e de outros grupos de convívio e pertencimento, adquirimos (e desistimos de) costumes e tradições regionais, adotamos orientações da mídia, padecemos (e exercemos) pressões sociais sobre o que comer, quando, como, onde, etc. E, assim, de tantas outras formas, vamos construindo e nos constituindo em nossas práticas alimentares. Essas práticas nos acompanham e revelam diversos aspectos nossos, pois, como afirma o antropólogo Sidney Mintz, a comida está vinculada ao "sentido de nós mesmos e à nossa identidade social" (2001, p. 31), articulando aspectos de nossa experiência sociocultural e pessoal. Porém, nem sempre temos a oportunidade de refletir sobre como nossas práticas alimentares foram sendo construídas ao longo da nossa vida. Diez Garcia (2005, p.278) define as práticas alimentares como:

\footnotetext{
Os procedimentos relacionados à alimentação de grupos humanos (o que se come, quanto, como, quando, onde e com quem se come; a seleção de alimentos e os aspectos referentes ao preparo da comida) associados a atributos socioculturais, ou seja, aos aspectos subjetivos coletivos e individuais associados ao comer e à comida (alimentos e preparações e aquilo que pensamos que comemos ou que gostaríamos de ter comido).
} 
Uma abordagem educacional da alimentação visa à construção de práticas alimentares saudáveis, considerando o caráter multidimensional da alimentação, "produto da interação de componentes biológicos, ecológicos e socioculturais" (DIEZ GARCIA, 2005, p.277). Como mencionamos anteriormente, nossos/as estudantes estavam familiarizados com 0 conhecimento biológico e, em alguns casos pontuais, ecológico da alimentação. Assim, era fundamental fazer emergir os aspectos socioculturais envolvidos para a construção de uma visão multidimensional, integral e não hierárquica.

Explorar a própria experiência de vida, a partir do trabalho com a memória, se mostrou como o método adequado para que aflorassem alguns dos diversos sentidos que licenciandos e licenciandas possuíam em relação à alimentação. Como afirma Mintz (2001, p.32), "Os hábitos alimentares podem mudar inteiramente quando crescemos, mas a memória e o peso do primeiro aprendizado alimentar e algumas das formas sociais aprendidas através dele permanecem, talvez para sempre, em nossa consciência (...)". Assim, a memória gustativa foi convocada no marco de uma intervenção didática, não como mera repetição de um fato que irrompe no presente, senão como trabalho. A memória, como trabalho, envolve posicionar-se desde um lugar ativo e produtivo. Como nos ensina Elizabeth Jelin, dizer que “a memória implica 'trabalho' é incorporá-la ao quefazer que gera e transforma o mundo social. " (2002, p. 14). Entendemos que, tal como expressa nossa epígrafe, são vastos os espaços onde aninham as lembranças, e, no processo de rememoração, algumas surgem imediatamente, outras devem ser procuradas com afinco. Nesse sentido, o trabalho com a memória requer que assumamos um papel ativo, conduzindo esse processo, nas palavras de Santo Agostinho: "Quando aí estou, peço que me seja apresentado aquilo que quero" (2001, p. 54)

$\mathrm{Na}$ formação inicial de professores, o trabalho com a memória, recuperando vivências e tornando-as experiência, constitui um momento de reapropriação de saberes pessoais e familiares que vão compor o leque de informações que servirá de base ao trabalho do/a futuro/a professor/a (TARDIF; RAYMOND, 2000). Nesses processos de trabalho com a memória, as narrativas constituem instrumentos importantes, pois tornam a experiência comunicável. Refletindo sobre a utilização de narrativas como instrumentos nos processos de formação de professores, Cunha (1997) comenta que o professor constrói sua performance a partir de diversas referências. Assim,

\footnotetext{
Provocar que ele organize narrativas destas referências é fazê-lo viver um processo profundamente pedagógico, onde sua condição existencial é o ponto de partida para a construção de seu desempenho na vida e na profissão. Através da narrativa ele vai descobrindo os significados que tem atribuído aos fatos que viveu e, assim, vai reconstruindo a compreensão que tem de si mesmo. (CUNHA, 1997, p.189)
}

Nesse sentido, a intervenção didática aqui analisada teve como objetivo principal a elaboração de narrativas em que se reconstruíssem memórias vinculadas à alimentação como forma de recuperar saberes que permitissem aproximações aos aspectos socioculturais relacionados à temática. A seguir, descrevemos a intervenção didática, tal como foi desenvolvida com os/as estudantes, e seu contexto. 


\section{A INTERVENÇÃO DIDÁTICA E SEU CONTEXTO}

As narrativas foram produzidas, por estudantes do curso Licenciatura em Ciências Biológicas, durante uma intervenção didática desenvolvida no marco da disciplina "Prática e Pesquisa em Ensino em Ciências Biológicas IV" (PPECB IV). A chamada PPECB IV é a quarta de uma sequência de seis disciplinas, que se caracterizam - em seu conjunto - como a parte da componente prática do currículo, em que licenciandos e licenciandas devem ter oportunidade de desenvolver conhecimentos e habilidades para realizar uma pesquisa empírica da área de educação. Esta PPECB IV, dando continuidade ao trabalho realizado nas anteriores, tinha como temática de ensino a Educação Alimentar.

A intervenção se iniciou com a leitura de dois textos, sobre memórias, que narravam lembranças familiares vinculadas à alimentação e preparação de alimentos (FARIA, 2012; LOIOLA, 2013). Durante a leitura em voz alta dos textos, e na conversa subsequente, foi perceptível as reações emotivas dos/as estudantes denotando a identificação pessoal com os conteúdos das narrativas. De fato, essa dinâmica teve o papel de mobilizar um processo de rememoração necessário para o desenvolvimento da atividade proposta. Na sequência, foi solicitado recordar e registrar, numa narrativa, as lembranças de hábitos alimentares, especialmente as práticas vivenciadas em família ou adquiridas ao longo da vida.

Durante o processo da escrita, observamos novamente, nos gestos de licenciandos e licenciandas, que diversas emoções afloravam: alguns sorriam; outros ficavam imbuídos em seus pensamentos, e iam escrevendo em conta-gotas; outros pareciam recuperar um objeto perdido e, em alguns momentos, paravam animadamente para comentar as lembranças com o/a colega ao lado. Antes de finalizar a aula, com a leitura livre de algumas das narrativas, tivemos a oportunidade de ouvir relatos vívidos sobre suas experiências de alimentação, numa diversidade de eventos: almoços de domingo, festas, aniversários, reencontros familiares, etc. Iniciamos, assim, um processo de recuperação e ressignificação dos sentidos da alimentação.

Nossa primeira impressão foi que eles realmente tinham se "doado" na atividade, pois as narrativas refletiam aspectos marcantes da história pessoal e familiar, mudanças nos percursos de vida, pessoas de referência, afetos, etc. Tendo em vista o importante potencial do conteúdo das narrativas, para pensarmos sobre diversos aspectos da alimentação, solicitamos a permissão dos vinte e um estudantes para escrever este artigo, entendendo esse processo como um momento importante de sua formação na temática abordada.

\section{ANALISANDO AS NARRATIVAS}

Para a análise das narrativas, utilizamos como método a análise de conteúdo temática, com o objetivo de compreender melhor o discurso e identificar os aspectos relevantes vinculados às práticas alimentares dos/as narradores/as. Segundo formulado por Laurence Bardin, a análise de conteúdo se serve de um conjunto de técnicas "visando obter, através de 
procedimentos sistemáticos e objetivos de descrição do conteúdo das mensagens, indicadores (quantitativos ou não) que permitam inferir conhecimentos relativos às condições de produção/recepção (variáveis inferidas) dessas mensagens. " (1977, p.42). Segundo Laurence Bardin, são três as fases que configuram a análise de conteúdo: a fase da pré-análise; a análise do material, e o tratamento dos resultados.

Durante a fase da pré-análise, cada narrativa foi identificada com um número e, no processo de leitura, se buscou encontrar núcleos de significados dentro de agrupamentos temáticos. Foi construído um quadro (Quadro 1) para a análise das narrativas, considerando inicialmente os elementos constitutivos da memória: acontecimentos, pessoas e lugares (POLLAK, 1992). No quadro, incorporamos, junto aos lugares, a variável tempo, porque, embora passado, presente e futuro estejam imbricados nos processos de reconstrução da memória, às vezes, há marcadores que se referem a algum momento específico e é a partir dele que se estruturam os sentidos sobre a memória. Como nos ensina Michael Pollak, "as preocupações do momento constituem um elemento de estruturação da memória" (1992, p.204). Esse passado e a forma como o enxergo, assim como o presente, influenciam minhas expectativas, projeções, certezas e incertezas em relação ao futuro.

Em seguida, sistematizamos, no quadro, alguns dos aspectos vinculados às práticas alimentares conceituadas por Diez Garcia (2005) e Maciel (2001). Como citado acima, essas pesquisadoras apontam diversos aspectos que caracterizam as práticas alimentares (o que se come, como, quando, onde, com quem e quanto), refletindo as práticas culturais de um grupo. Dessa forma, para o que se come foi incluído, no quadro, a coluna "Alimento", que permite identificar quais alimentos foram lembrados e, portanto, considerados relevantes para nossos/as narradores/as. A coluna "pessoas" serviu para registrar as pessoas lembradas pelos/as narradores/as e, também, se refere ao quem prepara os alimentos e com quem são consumidos, enquanto o onde e o quando já tinham sido contemplados na coluna lugar/tempo. Esclarecemos que a ordem no Quadro 1 não corresponde a uma sequência desses aspectos nas narrativas, pois, às vezes, era o alimento o primeiro a ser mencionado, enquanto, em outras narrativas, as pessoas foram lembradas inicialmente e, a partir delas, os alimentos ou práticas alimentares compartilhadas.

Houve aspectos, relacionados às práticas alimentares, pouco ou não explicitados nas narrativas. No primeiro caso, podemos citar o como se come, que remete às técnicas de preparação, consumo e conservação de alimentos (MACIEL, 2001); no segundo, o quanto, aspecto que caracteriza as práticas alimentares quantificando a comida consumida, que não esteve presente nas narrativas analisadas. Em compensação, foi apropriado incorporar uma coluna para refletir as formas de valorizar os alimentos, expressas em palavras e frases. Dessa maneira, contemplamos os aspectos subjetivos vinculados à alimentação manifestos, por exemplo, no uso destacado de adjetivos (a qualificação). Numa última coluna, denominada "Outros destaques", optamos por reunir aspectos que apareciam com relevo em algumas narrativas, mas que não eram contemplados nas colunas anteriores, por exemplo, momentos de mudança nas práticas alimentares, a relação entre sentimentos e alimentos, entre outras. A 
seguir, apresentamos o quadro utilizado na fase da análise do material, exemplificando com uma das narrativas produzidas pelos/as estudantes.

QUADRO 1 - Quadro para análise de narrativas

\begin{tabular}{|c|c|c|c|c|c|c|}
\hline N. & $\begin{array}{l}\text { Acontecimento ou } \\
\text { fato lembrado }\end{array}$ & $\begin{array}{l}\text { Alimento } \\
\text { (O que se come) }\end{array}$ & $\begin{array}{l}\text { Qualificação do } \\
\text { alimento (aspectos } \\
\text { subjetivos) }\end{array}$ & $\begin{array}{l}\text { Pessoas } \\
\text { (quem/com } \\
\text { quem) }\end{array}$ & $\begin{array}{l}\text { Lugar/tempo } \\
\text { (onde/quando) }\end{array}$ & Outros destaques \\
\hline 03 & $\begin{array}{l}\text { Almoço de domingo } \\
\text { Comemorar feriados } \\
\text { Abraço da mãe } \\
\text { Aprender a cozinhar } \\
\text { com a mãe } \\
\text { Voltar para a casa } \\
\text { familiar } \\
\text { Fazer o jantar } \\
\text { Compartilhar } \\
\text { marmitas }\end{array}$ & $\begin{array}{l}\text { SEU arroz } \\
\text { Estrogonofe } \\
\text { Carne de panela } \\
\text { Lasanha de } \\
\text { brócolis } \\
\text { Pão de queijo } \\
\text { Doce de abóbora, } \\
\text { mamão e goiaba, } \\
\text { arroz de forno, } \\
\text { feijão com louro, } \\
\text { salada de palmito } \\
\text { e purê de batata }\end{array}$ & $\begin{array}{l}\text { "Era -quase- } \\
\text { saudável, mas a } \\
\text { prioridade era ser } \\
\text { saboroso." } \\
\text { "Deus como ela } \\
\text { consegue não } \\
\text { consultar nenhum } \\
\text { manual e fazer uma } \\
\text { obra de arte" }\end{array}$ & $\begin{array}{l}\text { Mãe/ } \\
\text { Comensais: } \\
\text { Parentes (5 } \\
\text { irmãos, } 5 \\
\text { cunhadas, } 10 \\
\text { sobrinhos e } 3 \\
\text { filhos), amigos e } \\
\text { forasteiros, } \\
\text { vizinhos, colegas } \\
\text { da universidade }\end{array}$ & $\begin{array}{l}\text { - Casa } \\
\text { familiar/8 anos } \\
\text { - "eu moro } \\
\text { fora" } \\
\text { (universidade)/ } \\
\text { atual }\end{array}$ & $\begin{array}{l}\text { - "Minha mãe é } \\
\text { demais!" = seus } \\
\text { sentimentos } \\
\text { - Vegetarianismo: } \\
\text { "sendo a 'ovelha } \\
\text { negra' da família } \\
\text { (sou vegetariana)" }\end{array}$ \\
\hline
\end{tabular}

Fonte: Quadro elaborado pelas autoras.

Considerando que a análise de conteúdo foi temática, balizada pelo quadro acima, para a discussão de dados, optamos por organizar o tratamento dos resultados nos seguintes tópicos, apresentados a seguir: Os tempos da memória, Compartilhar a mesa, $O$ valor dos alimentos, Comida de avó e Mudanças na alimentação.

\section{Os tempos da memória}

O primeiro aspecto que merece destaque nas narrativas produzidas pelos/as estudantes diz respeito ao processo de rememoração. Como dissemos, para eles/as, "recordar" (do latim: "re": voltar a, e "cor-cordis": coração) significou voltar a passar pelo coração. Portanto, no processo de rememoração, emergiram diversas emoções vinculadas a essas vivências que foram trazidas do passado e revisitadas à luz da situação atual. Mesmo se tratando de uma atividade pontual e delimitada, os/as licenciandos/as se envolveram nesse processo e as emoções foram perceptíveis pelas docentes que acompanhavam o processo de escrita, assim como estiveram explícitos no conteúdo das narrativas produzidas.

"A alimentação diz muito sobre a nossa história, sobre os laços familiares de carinho e afeto que mantivemos ao longo de toda a nossa história" (Narradora 14)

"Tudo o que pede que eu resgate na memória, se torna um momento em que me traz sorrisos, mas também lágrimas e uma imensa saudade, ainda mais algo relacionado à alimentação, pois eu perdi duas pessoas que cozinhavam bastante para mim, minha avó e meu noivo. [...]” (Narradora 9)

Quando trabalhamos com memória, é importante salientar que a situação atual imprime sua marca no processo de rememoração. Dessa forma, a memória é moldada historicamente, selecionando e focalizando determinados acontecimentos, enquanto outros são "esquecidos", num processo de reconstrução que é influenciado pelo momento que se vivencia hoje. Portanto, na análise das narrativas optamos por articular os acontecimentos 
rememorados com seu marco espaço-temporal. Assim, observamos que os fatos lembrados se referiam, principalmente, a dois momentos da vida dos/as narradores/as: a infância e o momento que se vivencia na atualidade. Visando refletir sobre diversos aspectos vinculados às práticas alimentares, inicialmente, focalizamos nos acontecimentos referentes à infância e, em seguida, nos relacionados ao momento atual.

Nossos/as narradores/as foram longe na memória das práticas alimentares, iniciando com o aleitamento materno e a incorporação dos primeiros alimentos, como foi reconstruído numa das narrativas a partir da rememoração da criação dos irmãos mais novos:

\begin{abstract}
“Apesar de não lembrar como era minha alimentação quando bem pequeno acredito que tenha sido muito parecida com a de meus irmãos menores. Quando começavam a largar o peito, lembro que a primeira coisa que minha mãe lhes dava de diferente era maçã, cortada ao meio, e amassada com uma colher, e que eu costumava comer o que sobrava da maçã (com a colher também, apesar de saber já mastigar). " (Narrador 17)
\end{abstract}

Nesse trabalho com a memória, foram recordados acontecimentos da infância como a chegada da escola, a visita de familiares, as refeições na casa das avós, dentre outros, porém todos tinham como marco preponderante o cotidiano no lar familiar, como exemplificamos nos excertos abaixo.

\footnotetext{
"Me recordo dos tempos em que, ao chegar da escola, me deparava com uma assadeira cheia de pães caseiros e roscas doces que surgiam para acalentar as tardes frias e chuvosas, derreter a manteiga que era abraçada calorosamente pelas fatias" (Narradora 15)

"Lembrou-me quando eu chegava em sua casa e ela [a avó] me abraçava me dizendo logo que havia feito pão caseiro para mim, como eu me deliciava, era de um sabor único que só ela sabia qual ingrediente necessário para ficar com aquele sabor. " (Narradora 2)
}

Também foram lembrados os clássicos almoços de domingo, distinguidos dos outros dias da semana, pois se caprichava mais nos pratos, a família se reunia e os vínculos familiares se renovavam. Muitos se lembraram do cardápio de domingo, que se estabelece pela força do hábito e que vira "tradição".

\footnotetext{
"Não precisava ser domingo para ela caprichar e me fazer pedir bis. Contudo, preciso confessar que, aos domingos, até os vizinhos iam pra rua sentir o perfume que exalava da nossa cozinha. " (Narradora 3)

"E no domingo aquela festa. A casa cheia, todos ajudando a finalizar, e comendo por etapas para que todos pudessem se sentar à mesa para comer. " (Narrador 20)

"O cardápio tão tradicional de domingo: macarrão com molho vermelho, carne com batatas e salada de maionese. O incrível é nunca me enjoar de comer isso, pelo contrário, só de saber que aos domingos comerei aquela carne com batatas minha boca se enche de água! ” (Narradora 7)
}

Para um dos narradores, não foi o almoço de domingo o rememorado, e sim o almoço de sábado na casa da avó, a família toda se congregava para comer feijoada. Para o narrador, a memória desse almoço também "dá até água na boca". Todo sábado, junto com sua família pegava o ônibus para "a Vila Virginia (bairro de residência de minha avó), bom lembro que 
ao dobrar a esquina, algo tomava conta de meus sentidos, em que por algum motivo eu sentia o cheiro e o gosto daquela 'refeição dos deuses"' (Narrador 21).

A infância também foi o marco que permitiu explorar o caráter lúdico da preparação de alimentos, experiência compartilhada com as pessoas adultas da família, como refletem as narrativas a seguir.

"O meu pai sempre foi o 'mestre Cuca', o cozinheiro da família, o oficial chef das festas de final de ano e o cúmplice nas horas em que nos metíamos a fazer algo na cozinha, aquelas bagunças de crianças enfarinhadas. " (Narradora 20)

"Durante tardes animadas, quando uma tia de outra cidade vinha visitar, passávamos o tempo com minha madrinha fazendo pão. Elas, os pães grandes e eu, um pequenininho. Amolecer o fermento, sovar, passar a massa pelo cilindro. Depois, deixar crescer em um quarto escuro. Provar a massa crua e depois de assado, comelo quente com manteiga." (Narradora 12).

Nessas interações, em que se "brinca" de comidinha uma série de saberes começa a ser transmitida. Assim, também os momentos em que presenciam adultos preparando a comida, as crianças começam a se envolver em processos de transmissão de conhecimentos culinários.

"Aos 8 anos, meu ser gritava por aprender a fazer o SEU arroz. O estrogonofe, ensinou. A carne de panela, aprendi. A lasanha de brócolis, errei 2 vezes, e consegui. O pão de queijo, ficou melhor que o dela - e ela admite isso! Minha mãe é demais!" (Narradora 3)

Em duas das narrativas as memórias da alimentação, mesmo da infância, estavam mais relacionadas com o trabalho do que com o brincar. Uma das narradoras comentou que, quando criança, vendia no bairro, de porta em porta, as unidades extras dos pães caseiros elaborados pela avó materna; enquanto outra das narradoras rememorou sua participação na produção familiar de alimentos, como se transcreve a seguir:

\footnotetext{
"Quando crianças, eu e meus irmãos ajudávamos meu pai no campo, com diversas tarefas, uma delas distribuir o leite que havíamos tirado pela manhã. Lembro-me como se fosse hoje, ao chegarmos em casa com o restante do leite o sorriso de minha mãe. Tomávamos leite com café, fazíamos queijo freso, iogurte, qualhada [coalhada], entre outros derivados do leite. Toda minha infância tive alimentação dentro do campo, meu pai fazia o plantio, a colheita e minha mãe ficava com a parte doméstica. Não tínhamos dinheiro algum, mas éramos muito felizes. " (Narradora 11)
}

Todos esses acontecimentos rememorados e, sem dúvida, muitos outros configuram a infância como um momento marcante na construção de práticas alimentares. Como afirma Sidney Mintz (2001), durante a infância se dá a socialização alimentar, e esse primeiro aprendizado permanece através do tempo, assim como foi explicitado de diferentes formas pelos/as nossos/as narradores/as.

Rememorar é reconstruir o passado, repensando as vivências à luz do tempo presente que, como na revelação de uma fotografia, imprime um tom à imagem retratada. Assim, houve quem avaliou, no presente, a educação alimentar recebida na infância como "saudável", como a narradora 18 que disse: "Minha família sempre tendeu a um lado mais saudável, a mesa sempre composta com salada e guarnições diversas; desde criança sou 
acostumada a comer grãos, legumes, verduras, frutas, sucos, mel entre outros (...)". Contudo, nem sempre essa fase da vida foi explorada em sua potencialidade para a educação alimentar. Nesse sentido, uma das narradoras manifestava a falta de memórias marcantes sobre suas práticas alimentares.

\begin{abstract}
"Recordo-me pouco sobre meus hábitos alimentares da infância, talvez porque não tenha tido muitas experiências gustativas marcantes. Meus pais sempre trabalharam muito e por isso optavam pelos alimentos mais práticos e menos trabalhosos, inclusive brinco com as pessoas quando me perguntam: como você não gosta de doce de abóbora ou doce de banana? Sempre respondo: Porque minha mãe não me ensinou a comer! " (Narradora 19)
\end{abstract}

Nesse tópico, foi evidenciada a estreita relação entre a alimentação e os afetos. Também que nosso gosto foi sendo construído desde a mais tenra infância. Recuperamos a dimensão lúdica do preparo dos alimentos, como momentos de brincadeira e de aprendizagem de saberes culinários. Ademais foi possível refletir sobre a produção e preparo de alimentos como trabalho, presente em algumas das narrativas. A seguir, abordamos a comensalidade como valor atrelado às práticas alimentares.

\title{
Compartilhar a mesa
}

A comensalidade refere-se ao com quem comemos, envolve o compartilhar os alimentos, transformando o ato alimentar em um acontecimento social (MACIEL, 2001). A palavra "companheiro" (como no francês compagnone, no inglês companion) provém de cum panem, "os que compartilham o pão". Assim, a comensalidade, o "comer juntos", é o momento de reforçar a coesão do grupo, pois ao partilhar a comida, partilham sensações, tornando-se uma experiência sensorial compartilhada (MACIEL, 2001, p. 150). Nas narrativas, foi evidente que com quem se come era um aspecto relevante nas práticas alimentares de nossos/as narradores/as.

\footnotetext{
"Não importa a refeição - almoço, jantar, café da manhã ou da tarde -, se estivermos todos no mesmo lugar, faremos as refeições juntos. Às vezes, não conversamos; cada um com os pensamentos perdidos em seus próprios mundos, mas estarmos sentados juntos, acalma o espírito e transmite uma sensação única de felicidade. Isso - esse sentimento - torna a comida melhor! Nem sempre a refeição é elaborada: existem dias em que comemos arroz com ovo, existem dias que comemos camarão. Cada refeição é inconstante. Nós não." (Narradora 5)

"Gosto muito das refeições em família, nas datas comemorativas, porque é o momento em que mais há diversidade de alimentos na mesa, e é o momento para rir e matar as saudades. " (Narrador 10)
}

Porém, a situação atual de vários de nossos/as narradores/as se caracteriza por estar longe da família e, assim, longe também de usufruir essa comensalidade, pois estudam "do outro lado do estado". A narradora 9 expressava assim sua visão da comensalidade a partir do momento que atualmente vivencia: 
“(...) o simples ato de se alimentar, que todo ser faz, desde bactérias até nós, se torna algo memorável e uma celebração (quando se come em família). Isso era nítido para mim, mas foi fazer maior sentido quando eu sai de casa para estudar, onde eu almoçava e jantava quase todos os dias no restaurante universitário, que por sinal é quase um martírio, assim, como no texto, quando eu visito minha família, o jeito deles me agradarem e mostrarem a saudade é cozinhando (...)”

Nossos/as narradores/as pertencem a uma geração que vivenciou a comensalidade e que, portanto, a valoriza. Nas narrativas, ficou explícita a afetividade envolvida no ato alimentar, e a visão de que a mesma influencia positivamente a alimentação. Alves \& Boog (2007), em pesquisa sobre práticas alimentares de estudantes universitários, exploraram a influência da companhia na qualidade da alimentação, revelando que, para quase $80 \%$ dos estudantes entrevistados, comer sozinho ou acompanhado tinha um efeito na qualidade da alimentação. Eles apontaram que a afetividade tinha uma influência positiva. Contudo, a mesma parecia não estar presente quando se comia no restaurante universitário (bandejão). Talvez, a experiência inicial de comer no restaurante universitário seja um equivalente ao "table d'hôte" (mesa de hóspedes), descrito por Georg Simmel, há pouco mais de um século, em que o ato de comer expunha, segundo ele, sua finalidade materialista.

\begin{abstract}
Aqui as pessoas se encontram apenas e dominantemente pela razão de comer; estar junto de alguém não é a situação desejada com um valor em si, mas, ao contrário, apesar de estar compartilhando uma mesa com todas essas pessoas, de modo algum se pressupõe que se entre em relacionamento com elas. (SIMMEL, 2004, p.163)
\end{abstract}

Nas últimas décadas, céleres mudanças nos estilos de vida, a urbanização, a globalização, a saída das mulheres ao mercado de trabalho ou por outros motivos, produziram transformações nas formas de consumo alimentar, afetando "o nosso paladar e os aportes nutritivos, trazendo novos padrões alimentares, novos costumes, hábitos e práticas alimentares." (SANTOS, 2006, p. 10). Nessa sociedade que se "mcdonaliza", vivenciar a comensalidade é uma experiência cada vez mais difícil. Como formas de resistência à perda de um dos sentidos da alimentação, que é a sociabilidade, alguns restaurantes europeus retomaram a prática das mesas de uso coletivo para o cultivo da comensalidade. Um costume que, na década de 1970, foi abandonado, começou a se revitalizar na entrada do século XXI, chegando ao Brasil em anos mais recentes. Como uma forma de tentar fazer o freguês se sentir "em casa", lembrando-o de que compartilhar os alimentos é um ritual coletivo.

A comensalidade esteve presente em quase todas as narrativas, transcendendo ascendências: italiana, espanhola, paraguaia e afrodescendente. Portadores de uma memória de alimentação em que, muitas vezes, se salienta o comer juntos, a comensalidade e sua força

\footnotetext{
${ }^{2}$ A meados da década de 1990, o sociólogo George Ritzer acunhou o termo "mcdonaldização" para descrever um fenômeno social, segundo o qual os princípios que orientavam a produção da empresa de comidas rápidas Mc Donald, permeavam a sociedade. Num contexto mais próximo, de nós e da discussão aqui construída, Santos (2006) refere-se à "mcdonalização" da sociedade como um processo histórico em que o capitalismo estadunidense impõe estilos de vida, afetando o âmbito da alimentação promovendo o consumo de alimentos industrializados, tendendo à homogeneização do gosto, à eliminação das culinárias locais e tradicionais etc. Além de todos os efeitos que esse fenômeno de massas tem no âmbito da alimentação, o professor Santos salienta o impacto nas relações sociais que são construídas e reconstruídas nas práticas alimentares.
} 
socializadora. Na situação atual, em que deixou de ser parte do cotidiano, essas vivências são ressignificadas.

"Enfim, nessa família meio italiana, meio espanhola, enfim, brasileira temos uma alimentação diversificada, gosto peculiares, mas que aos domingos (não mais todos) a alimentação transforma-se em algo além do nutrir, é um momento de reencontro, de conversar, envolver-se e recordar." (Narradora 4)

Retornar a casa é reencontrar-se com os sabores e trazer um pouco deles para este lado do estado, e compartilhá-los com amigos e colegas. Esta é uma prática muito comum, no ambiente universitário, que possibilita a ampliação do nosso horizonte culinário a partir de conhecimentos e experiências trazidas por colegas de diferentes estados, cada um com uma história de sabores, de aromas, de gosto, etc., assim como sua ressignificação.

\footnotetext{
"Hoje eu moro fora, bem longe dela (mãe) e me recordo do seu abraço toda noite para conseguir dormir enquanto ela está lá, do outro lado do estado cozinhando para atrair amigos só pra contar das minhas conquistas aqui. Toda vez que volto pra casa, ela me espera com doce de abóbora, mamão e goiaba; arroz de forno, feijão com louro, salada de palmito e purê de batata. [...] Quando volto pra faculdade, não dispenso suas marmitas e ainda distribuo para todos que moram comigo. $\mathrm{O}$ mundo precisa de SUAS mãos. " (Narradora 3)

"Quando retorno para minha cidade também tem aquelas comidas que tenho vontade e estarão lá na primeira refeição. ” (Narradora 13)
}

Apenas um narrador referiu-se ao consumo de um alimento como ato solitário. Também, a diferença de todas as outras narrativas, em que se mencionaram alimentos de produção caseira, tratou-se de um alimento de produção industrial. O narrador 6 relatou a aquisição, no supermercado, de um flã com calda de morango, e seu consumo em casa, da seguinte maneira:

\begin{abstract}
"Pouquíssimos momentos na minha vida são tão prazerosos quanto comer um flã com calda de morango. Tudo no processo que envolve ele é maravilhoso. Desde correr ao supermercado, ir para a geladeira, e achar especificamente ele. A ansiedade de chegar em casa e esperar ele gelar mais um pouco, é incontrolável. A melhor parte, melhor até que comer ele, é por ele de ponta cabeça, espetar o fundo do potinho com uma agulha, e observar o desenho que se forma no prato com a calda de morango. Nem o melhor pudim da minha avó, é melhor que esse flã. " (Narrador 6)
\end{abstract}

Nesse tópico, ficou evidente a dimensão sociabilizadora da alimentação. Foi possível reconhecer a comensalidade como valor adquirido nas práticas alimentares vivenciadas, e refletir sobre as mudanças atuais nos estilos de vida, e o impacto das mesmas, nas formas em que nos alimentamos e nos relacionamos. Foi salientado que assim como adquirimos valores nas práticas alimentares também os transmitimos.

\title{
O valor dos alimentos
}

Um aspecto relevante, quando abordamos as práticas alimentares, é referente ao que se come. No caso das narrativas analisadas, uma característica comum de quase todos os alimentos lembrados é que eram caseiros. Apenas em uma das narrativas foi rememorado o consumo de um alimento industrializado, como mencionamos acima, pelo narrador 6 . 
Quando ele compartilhou na roda de conversa sua memória, disse que a despeito de qualquer outra comida feita pela mãe ou avó, que eram ótimas cozinheiras, o gosto desse alimento sempre era o mesmo. Os outros alimentos lembrados foram feitos em casa por pessoas da família dos/as narradores/as e/ou por eles/as mesmos/as.

A lista é variada e, como referimos acima, nossos/as narradores/as não se referiram a quantidades (o quanto), senão a qualidades, explicitando diversas formas de diferenciar e valorizar os alimentos. Assim, foi possível identificar aspectos subjetivos vinculados à alimentação manifestos, por exemplo, no uso destacado de adjetivos (a qualificação). Para Kerbrat-Orecchioni (1993), os adjetivos subjetivos manifestam a presença do enunciador no interior do enunciado e refletem seu compromisso afetivo, "enunciam ao mesmo tempo que uma propriedade do objeto ao que determinam, uma reação emocional do sujeito falante frente a esse objeto. " (p.111). Para a linguista, existem diversas formas de manifestar a subjetividade em relação aos objetos, assim o valor afetivo pode ser inerente ao adjetivo, manifesto em signos tipográficos, ou na anteposição do mesmo ao substantivo qualificado, e pela utilização de figuras poéticas, como metáforas.

No caso das narrativas analisadas, identificamos três formas diferentes de expressão de subjetividade em relação aos alimentos, a partir de uma análise linguística. A primeira utiliza adjetivos vinculados ao campo lexical da alimentação e da culinária. Outra forma de expressão de subjetividade evidenciada se vale de palavras, ou frases, para referir relações de pertencimento dos alimentos. Finalmente, reconhecemos a utilização de recursos poéticos na tentativa de expressar visões, sensações, sentimentos, etc., provocados pelo consumo de alimentos.

A primeira está caracterizada pela utilização de adjetivos que correspondem ao campo semântico da alimentação, em ocasiões, enfatizados pelo uso de advérbios. Assim, para nossos/as narradores/as, a comida tem um "Gosto delicioso", pode ter um lado mais "saudável", ou "quase- saudável, mas a prioridade era ser saboroso" (grifos nossos). Contudo, por falta de tempo, há quem opta por "alimentos mais práticos e menos trabalhosos". O cardápio de domingo é "tão tradicional", as massas são "fofas, molhadas e cremosas". Alguns alimentos merecem destaque na memória dos/as narradores/as: "Do que me lembro na infância é da comida caseira e saborosa da minha avó materna, tão simples, mas tão bem-feita." (Narrador 16); "O feijão que nunca encontrei tão saboroso em qualquer outro lugar. $\mathrm{O}$ arroz tão solto que ela [a avó] sempre fazia com a mesma exata medida." (Narradora 7).

Um segundo caso é a expressão de relações de pertencimento vinculadas ao preparo e consumo dos alimentos. O caso mais comum foi é uso do adjetivo possessivo em terceira pessoa (seu/sua), referindo-se à pessoa que preparou o prato de uma forma que o distingue de qualquer outro do gênero. Assim, a narradora 3 mencionava: "Aos 8 anos meu ser gritava por aprender a fazer o SEU arroz."; enquanto a narradora 14, referindo-se à comida da avó, ressalta: "lembro como se fosse hoje, de todas as vezes que comi o seu arroz com feijão, sua batata frita, o melhor bife à milanesa do mundo, o seu pão caseiro inigualável, seu bolo de 
fubá, entre outras coisas que só ela sabia fazer e que tinham um sabor incomparável.”. Em relação ao consumo, pelo fato de serem os destinatários do alimento, alguns narradores tornaram o alimento como algo próprio, e se referem ao mesmo expressando essa relação de forma indireta ou pelo uso de adjetivos em primeira pessoa. A comida vegetariana, preparada pela avó de uma das narradoras, se transforma na "Comida da Má [apelido]", a sobremesa preparada pela mãe de outra narradora torna-se "O meu doce preferido, que a família inteira ama!"”.

Finalmente, identificamos narrativas em que a forma de caracterizar os alimentos não está diretamente relacionada ao campo da culinária, mas que, tentando exprimir sensações, sentimentos, etc., se vale de diversos recursos poéticos, como a metáfora. Dessa forma, revelam o efeito sinestésico dos alimentos que consumimos, e a maneira como eles se gravam na nossa memória. Roça à hipérbole referir-se aos pratos como sensacionais, incomparáveis, de sabores únicos, incríveis, e, até, "divinos!!". A comida da avó tem "Sabor de infância que nunca mais vou sentir"; a feijoada é quase personificada para receber o afeto da narradora que se refere a ela com um: "Tão querida". Assim, também, o flã do narrador 6 se torna "ele".

Diversos recursos poéticos auxiliam nossos/as narradores/as a expressar seu deslumbramento diante da capacidade humana no ato culinário, como se reflete na pergunta retórica de uma das narradoras: "Deus como ela consegue não consultar nenhum manual e fazer uma obra de arte" (grifo nosso). Para alguns, os alimentos conseguiriam facilmente atravessar as fronteiras deste mundo, pois entendem que é possível "transformar um simples arroz e feijão em um manjar dos deuses", e sem falar da feijoada, "um alimento digno dos deuses". Como afirma Mariana Corção, a memória gustativa provoca a necessidade de procurar, em si próprio, o que é essa sensação, buscando nos vestígios do passado (2006). Sem os limites de um discurso lógico-racional, navegam pelos mares da poesia para transmitir-nos o que esse alimento representa para eles mesmos.

O consumo dos alimentos lembrados está vinculado com momentos prazerosos, e alguns dos/as narradores/as se interrogam sobre o "mistério" que torna esses alimentos capazes de suscitar tantas sensações. Alguns suspeitam que passam por uma "mágica indecifrável" que os torna irreproduzíveis, outros arriscam que o ingrediente secreto seja o "Toque do amor". Esse tópico revelou para nós uma janela que mereceria ser aberta num trabalho transdisciplinar entre Ciências e Literatura, considerando poetas e escritores que abordaram o tema da alimentação, como Pablo Neruda, Isabel Allende, Laura Esquivel, entre outros.

\section{Comida de avó}

Como destacado por diversos autores, as narrativas refletem que, na abordagem da questão da alimentação, emergem também as relações familiares e, principalmente, as de gênero (WOORTMANN, 1986; MINTZ, 2001). Nas narrativas analisadas, as relações de gênero estão articuladas às relações de geração, pois, nas memórias recuperadas, são as avós que despontam como principais protagonistas. Na retórica de uma das narrativas: "Quem 
nunca se lembra das receitas de vó? ”. Seguem algumas mães, bisavós e uns poucos homens, que têm a coragem de se aventurar pelo universo culinário e são reconhecidos como: boleiro da casa, mestre Cuca, cozinheiro da família e até oficial chef.

"Do que me lembro na infância é da comida caseira e saborosa da minha avó materna, tão simples, mas tão bem-feita. (...)” (Narrador 6)

“(...) a comida que me faz mais lembrar de momentos bons é a comida da minha avó, a melhor comida que já comi na vida, mas que infelizmente não poderei mais saborear, porque minha avó já se foi. (...)" (Narradora 14)

Alguns narradores/as reconheceram que careciam de memórias "próprias" sobre as vivências culinárias com as avós. Contudo, estas foram reconstruídas a partir dos relatos de outros membros da família. No trabalho com a memória, as pessoas de nosso grupo de pertencimento desempenham um papel fundamental, pois não só compartilham conosco vivências, como também nos auxiliam quando precisamos rememorá-las. Como afirma Maurice Halbwachs, "Recorremos a testemunhos para reforçar ou enfraquecer e também para completar o que sabemos de um evento sobre o qual já temos alguma informação (...)" (2006, p. 29). Assim, uma de nossas narradoras manifestou:

\begin{abstract}
"Eu era muito pequena, mas sei que tradição de se fazer e comer em família a tão querida feijoada veio da minha avó materna. Quando se refere a minha avó, lembro apenas das histórias que meus irmãos mais velhos me contavam sobre os almoços de domingo, sobre os pedaços de porco que minha vó insistia em colocar na feijoada mesmo que ninguém quase os comesse. Lembro muito do quanto sempre desejei lembrar mais desses detalhes, dessa época. " (Narradora 20)
\end{abstract}

As avós, reconhecidas como portadoras de saberes e de um saber fazer culinários, muitas vezes herdados dos antepassados, também eram apreciadas por deter o saber sobre os gostos dos membros da família, e possuir a capacidade de comprazê-los. Nesse sentido, a narradora 13 comentava: "É só falar para minha avó que estou com vontade daquele bolo de fubá que ela já está com ele no forno e o café passando. (...). É minha vó. É minha mãe.”. É interessante pontuar que, em pesquisas sobre alimentação, as mulheres e, especificamente, as mães ocupam um lugar central no preparo dos alimentos (ASSUNÇÃO, 2008). Contudo, no caso das narrativas analisadas, são as avós que assumem esse papel. Talvez, em virtude de nossos/as narradores/as pertencerem a uma geração mais jovem, são filhos e filhas de mães que saíram para trabalhar fora de casa e, em alguns casos, as avós exerceram parte da maternagem. Como reconhece a narradora 13, "É minha avó. É minha mãe". Outra narradora referiu ter sido criada pelas avós, enquanto outros mencionaram que costumavam ser recebidos pelas avós quando chegavam da escola.

As memórias reconstruíram um cotidiano em que foram compartilhados saberes, gostos, valores vinculados às práticas alimentares de uma geração que hoje lida com novos estilos de vida, bem diferentes das comidas caseiras, "bem-feitas", compartilhadas em família. Como se posicionam nossos/as narradores/as em relação aos saberes, sabores e valores com que foram nutridos? 
“As lembranças quanto a minha avó paterna também me vem à mente. Como ela sempre soube utilizar temperos com maestria, transformar um simples arroz e feijão em num manjar dos deuses, combinar todas as formas e gostos possíveis de adoçar nossas vidas com seus dotes culinários. Mas, infelizmente, hoje em dia não conseguimos usufruir dessas maravilhas como antes. Pois, ela se encontra debilitada e, por mais que toda sua vida tenha esbanjado o seu dom, por ironia do destino, ela não consegue nem sentir o cheiro da comida por conta de uma anemia que insiste em se manter conosco. Mas agora, eu cozinho para ela e quero que esse simples gesto seja tão importante para o bem-estar dela como foi para mim na infância." (Narradora 15)

As narrativas refletem diversas formas de apropriação do legado das avós, que passa pelo aprendizado de receitas, pelas tentativas de reproduzi-las, pelo compromisso com a transmissão desses saberes, sabores e valores às gerações vindouras, entre outros. Como manifestava a narradora 8: "Definitivamente vovó Aparecida conseguiu passar o legado de receitas, pelo menos para mim (em segredo) e com certeza passarei seus sabores aos meus filhos.".

\section{Mudanças na alimentação}

As práticas alimentares como práticas sociais também envolvem mudanças, pois, assim como a tradição, a inovação tem um lugar à mesa. Nas narrativas analisadas, um momento de mudança se refere ao que se come, e está marcado pela adoção do vegetarianismo, refletindo diferentes tipos de repercussões no ambiente familiar. Assunção (2008) salienta que as refeições são momentos de sociabilidade, de "comer junto", da coletividade, mas que neles as individualidades também aparecem. A pesquisadora identifica, no contexto de sua investigação, que essas individualidades eram valorizadas e respeitadas, principalmente pelas mães, entendendo que "cada um tem seu gosto" (p.7). No caso das narrativas aqui analisadas, podemos entender o vegetarianismo como a emergência de uma forma de individualidade que, às vezes, surge como "desgosto" pela carne e se remete à infância, acontecendo a mudança alimentar na adolescência ou em momento mais recente.

Em outros casos, é uma mudança progressiva que começa pela supressão da carne vermelha do cardápio que, às vezes, começa como promessa e vai sendo construída, posteriormente, como decisão. Assim, trata-se de uma escolha que se fortalece no contato com outros vegetarianos pertencentes a espaços de sociabilização, que não o familiar, como, por exemplo, a universidade ou o âmbito laboral. Contudo, as narrativas refletem que nem sempre essa escolha é respeitada e valorizada. Como manifesta a narradora 18: "carne nunca foi meu forte, meus pais tentaram, mas nunca aceitei, hoje escolhi ser vegetariana, mas ainda moro com meus pais, minha mãe sempre esconde a carne em algum lugar". É possível fazer duas feijoadas, como relatado numa narrativa, uma com todos os ingredientes e outra "light", para quem não gosta de orelha, rabo, pé e couro de porco, mas pensar numa feijoada vegetariana, para a maioria, carece totalmente de sentido. Assim, no nosso contexto cultural, a identidade do vegetariano se constrói como um "não ser", um traço de não pertencimento a esse núcleo familiar, ou na expressão de uma das narradoras é ser "a 'ovelha negra' da família (sou vegetariana) ". Contudo, o/a vegetariano/a consegue manter seu lugar à mesa. 


\begin{abstract}
"Quando completei quinze anos resolvi parar de comer a carne vermelha, começou como uma promessa e continuei. Minha avó respeitou minha escolha. Na universidade, conhecendo novas pessoas, novas perspectivas, acabei mudando alguns hábitos alimentares, minha avó também, porém ela devido à idade e saúde. Depois parei de comer frango. E agora? O que fazer aos domingos? O molho pode ser ao sugo, e o frango assado? Novamente minha avó entendeu e respeitou minha opção. Agora acrescentava-se salada e legumes a mesa. " (Narradora 4)
\end{abstract}

É importante frisar que essas mudanças no cardápio não se realizam sem resistências dos outros comensais. Em situação semelhante, outra narradora salientava que todos reclamavam da incorporação da comida vegetariana ao cardápio de domingo, mas era a primeira comida a acabar. Assim, observamos com Santos e Zanini (2008, p. 256) que o "pôr na mesa" envolve conflitos e negociações, e são as mulheres que exercem seu “"poder' e voz para introduzir ou rejeitar alimentos no universo doméstico, especialmente aquelas consideradas "inovações"'. Algumas mães e, principalmente, as avós respeitam os novos gostos. Talvez porque o princípio da comensalidade seja entendido como um valor mais forte, principalmente, por quem a cultiva como forma de manter os laços familiares. Assim, o vegetarianismo como emergência de uma individualidade envolve aprendizados, como explica o narrador 10: "hoje que sou vegetariano, ela [ $a$ mãe] prepara grão de bico ou soja ou simplesmente compra os ingredientes para eu cozinhar". Também a narradora 18 refere seus aprendizados culinários:

“Trabalhei mais de um ano em uma loja de produtos naturais, lá aprendi mais sobre vários temperos, vários grãos e vários chás, aprendi a tempeirar [temperar] e agora minha mãe sempre pede minha ajuda; inclui na minha alimentação (sempre quando posso) mais sabor e diversidade, e hoje os chás estão presentes diariamente, e meu amigos e conhecidos e família sempre me pedem ajuda quando querem diversificar ou aprender a se alimentarem. " (Narradora 18)

Nesse tópico, evidenciaram-se alguns conflitos que decorrem das mudanças na alimentação, e como estas envolvem negociações no âmbito familiar. Nas narrativas analisadas, o vegetarianismo implica o aprendizado de saberes culinários, dando certa autonomia, além da possibilidade de influenciar as práticas alimentares de outros comensais. A partir do vegetarianismo, é possível a discussão sobre nossos hábitos alimentares, questões relacionadas à produção dos alimentos e sustentabilidade, alimentos e saúde, entre outros.

\title{
5 ALGUMAS CONSIDERAÇÕES
}

O trabalho, com a memória das práticas alimentares, se revelou uma estratégia apropriada para aproximar licenciandos e licenciandas dos aspectos socioculturais da alimentação, como demonstram as discussões desenvolvidas ao longo deste texto. A reconstrução das memórias possibilitou compreender alguns dos significados atribuídos às práticas alimentares no marco das quais nossos/as estudantes se educaram e se educam, tanto no passado quanto no presente. A alimentação imprime marcas na memória, na identidade, na própria história. Como revelam as narrativas apresentadas, a infância constitui um momento marcante na experiência alimentar recuperada. Dessa época, guardam-se (ou não) saberes, sabores, aromas, afetos e, também, valores vinculados às práticas alimentares vivenciadas. $\mathrm{Na}$ \begin{tabular}{l|l|l|l|l|l|l}
\hline (C) ETD -Educ. Temat. Digit. & Campinas, SP & v.18 & n.3 & p.670-689 & jul./set.2016 & ISSN 1676-2592
\end{tabular} 
própria linguagem, é evidente que nossa relação com os alimentos vai além do ato alimentar enquanto ato fisiológico, implicando nossa subjetividade. $\mathrm{Na}$ construção dessa relação, as avós têm um papel marcante, reconhecido como herança e recuperado como projeto, no desejo de construir práticas alimentares semelhantes com as gerações vindouras. Da mesma forma, em que a "tradição" esteve presente nas narrativas analisadas, também a inovação tem seu lugar à mesa, como demonstra a adoção do vegetarianismo. Assim, as narrativas revelam que, também em termos alimentares, nos educamos ao longo da vida.

No trabalho com a memória, nossos/as estudantes se colocaram como atores em seu processo de formação, recuperando experiências e saberes vinculados às suas práticas alimentares, e compartilhando nas suas narrativas saberes, sabores, aromas, afetos e, também, valores de um passado que se leva consigo como parte da experiência vital. Nossos/as narradores/as são portadores/as de práticas alimentares marcadas por aspectos que deixaram de ser parte do cotidiano, mas permanecem na memória, podendo ser convocados e ressignificados em processos de formação docente a fim de torná-los ferramentas para futuras performances como educadores e educadoras.

\section{REFERÊNCIAS}

ALVES, Hayda Josiane; BOOG, Maria Cristina Faber. Comportamento alimentar em moradia estudantil: um espaço para promoção da saúde. Revista Saúde Pública, São Paulo, SP, v. 41, n. 02, p. 197-204, 2007. Disponível em: 〈http://goo.gl/6gmscK〉. Acesso em: 29 abr. 2016. ISSN 1518-8787.

ASSUNÇÃO, Viviane Kraieski. Comida de mãe: notas sobre alimentação e relações familiares. Anais eletrônicos... In: REUNIÃO BRASILEIRA DE ANTROPOLOGIA, 26., 2008, Porto Seguro, BA. Disponível em: 〈http://goo.gl/5yNnkg>. Acesso em: 12 jan. 2016.

BARDIN, Laurence. Análise de conteúdo. Lisboa: edições 70, 1977. 226 p.

BOOG, Maria Cristina Faber. Contribuições da educação nutricional à construção da segurança alimentar. Saúde em Revista, Piracicaba, SP, v. 06, n.13, p. 17-23. 2004. Disponível em: 〈http://goo.gl/kkS60U>. Acesso em: 29 abr. 2016.

CORÇÃO, Mariana. Memória gustativa e identidade: de Proust à cozinha contemporânea. Curitiba, 2006. Disponível em: 〈http://goo.gl/7KvJuf>. Acesso em: 03 fev. 2016.

CUNHA, Maria Isabel da. Conta-me agora! As narrativas como alternativas pedagógicas na pesquisa e no ensino. Revista da Faculdade de Educação, São Paulo, SP, v. 23, n. 01-02, p. 185-195. jan./dez. 1997. Disponível em: 〈http://goo.gl/G6d1XW>. Acesso em: 29 abr. 2016. ISSN 0102-2555.

DIEZ GARCIA, Rosa Wanda. A antropologia aplicada às diferentes áreas da nutrição. In: CANESQUI, Ana Maria; DIEZ GARCIA, Rosa Wanda (Orgs.). Antropologia e nutrição: um diálogo possível. Rio de Janeiro: Ed. FIOCRUZ, 2005, p. 275-286. 
FARIA, Roberta. Receita de família. Sorria, São Paulo, SP, n. 28, p. 17-18. 2012.

JELIN, Elizabeth. Los trabajos de la memoria. Madrid: Siglo XXI, 2002. 146 p. Disponível em: 〈http://goo.gl/pCSgd1>. Disponível em: 29 abr. 2016.

HALBWACHS, Maurice. A memória coletiva. São Paulo: Centauro, 2006. 222 p.

KERBRAT-ORECCHIONI, Catherine. La enunciación. De la subjetividad enel lenguaje. Buenos Aires: Edicial, 1993.307 p. Disponível em: 〈http://goo.gl/ltFX3y〉. Acesso em: 29 abr. 2016.

LOIOLA, Rita. Comida de mãe. Sorria, São Paulo, n. 31, p. 16-17. 2013.

MACIEL, Maria Eunice. Cultura e alimentação ou o que têm a ver os macaquinhos de Koshima com Brillant-Savarin? Horizontes Antropológicos, Porto Alegre, RS, v. 07, n. 16, p. 145-156. dez. 2001. Disponível em: 〈http://goo.gl/la511B >. Acesso em: 29 abr. 2016. ISSN 1806-9983.

MINTZ, Sidney. Comida e antropologia. Uma breve revisão. Revista Brasileira de Ciências Sociais, São Paulo, SP, v.16, n. 47, p. 31-41. out. 2001. Disponível em: <http://goo.gl/yZMWzj>. Acesso em: 29 abr. 2016. ISSN 1806-9053.

POLLAK, Michael. Memória e identidade social. Estudos Históricos, Rio de Janeiro, RJ, v. 05, n. 10, p. 200-212. 1992. Disponível em: 〈http://goo.gl/g1vItF〉. Acesso em: 29 abr. 2016. ISSN 2178-1494.

SANTO AGOSTINHO. Confissões. Livros VII, X e XI. Lisboa, 2001. Disponível em: <http://goo.gl/TwA08 >. Acesso em: 22 fev. 2016.

SANTOS, Miriam Oliveira; ZANINI, Maria Catarina. Comida e simbolismo entre imigrantes italianos no Rio Grande do Sul (Brasil). Caderno Espaço Feminino, Uberlândia, MG, v. 19, n. 01, p. 255-285. jan./jul. 2008. Disponível em: 〈http://goo.gl/1SES1T〉. Acesso em: 29 abr. 2016. ISSN 1981-3082.

SANTOS, Carlos Roberto Antunes dos. O Império Macdonald e a mcdonalização da sociedade: alimentação, cultura e poder. Anais eletrônicos... In: SEMINÁRIO FACETAS DO IMPÉRIO NA HISTÓRIA, Curitiba, PR, 2006. Disponível em: 〈http://goo.gl/y82N99〉. Acesso em: 04 abr. 2015.

SIMMEL, Georg. Sociologia da refeição. Estudos Históricos, Rio de Janeiro, RJ, n. 33, p. 159-166, jan./jun. 2004. Disponível em: 〈http://goo.gl/5vigKt〉. Acesso em: 29 abr. 2016. ISSN 2178-1494.

TARDIF, Maurice; RAYMOND, Danielle. Saberes, tempo e aprendizagem do trabalho no magistério. Educação \& Sociedade, Campinas, SP, v. 21, n. 73, p. 209-244. dez. 2000. Disponível em: 〈http://goo.gl/i2d1L〉. Acesso em: 29 abr. 2016. ISSN 1678-4626. 
WOORTMANN, Klass. A comida, a família e a construção do gênero feminino”. Dados, São Paulo, SP, v. 29, n. 01, p. 103-130. 1986. Disponível em: 〈http://goo.gl/TkQN16>. Acesso em: 20 de abr. 2015.

\section{Agradecimentos}

Agradecemos aos alunos e alunas do curso de Licenciatura em Ciências Biológicas por terem compartilhado conosco suas memórias e experiências enriquecendo o processo educativo que vivenciamos, e por terem cedido suas narrativas para esta discussão. Também, somos gratas ao apoio da CAPES e do CNPq.

\section{ADRIANA MARCELA BOGADO \\ Doutora em Sociologia - Universidade Federal de São Carlos - UFSCar Professora pesquisadora - Centro de Educação e Ciências Humanas UFSCar, São Carlos, SP - Brasil - E-mail: adrianistica@ hotmail.com \\ DENISE DE FREITAS \\ Doutora em Educação - Universidade de São Paulo - USP Professora Associada - Universidade Federal de São Carlos, UFSCar São Carlos, SP - Brasil - E-mail: dfreitas2011@gmail.com}

Recebido em: 29/04/2016 Aprovado para publicação em: 11/07/2016.

\section{Como citar este documento:}

BOGADO, Adriana Marcela; FREITAS, Denise de. A reconstrução de memórias da alimentação na formação inicial de professores de ciências: um reencontro com saberes, sabores, aromas e afetos. ETD - Educação Temática Digital, Campinas, SP, v. 18, n. 3, p. 670-689, ago. 2016. ISSN 1676-2592. Disponível em: <http://periodicos.sbu.unicamp.br/ojs/index.php/etd/article/view/8645410>. Acesso em: 30 ago. 2016. doi:http://dx.doi.org/10.20396/etd.v18i3.8645410. 